\title{
Estratégias enunciativas na produção do efeito de imparcialidade em notícias jornalísticas
}

Ricardo Lopes Leite

Otavia Marques de Farias

Resumo: Este trabalho investiga como as estratégias enunciativas produzem o efeito de sentido de imparcialidade em notícias jornalísticas. Para isso, utilizando o referencial teórico da semiótica discursiva, analisamos as operações enunciativas de debreagem e embreagem mobilizadas em duas notícias, uma publicada em O Povo e outra no Diário do Nordeste, ambos jornais de Fortaleza - Ceará. Observamos que, ao regularem a presença da enunciação no enunciado, as operações enunciativas criam diferentes graus de isenção ou comprometimento, tanto do enunciador quanto dos actantes do enunciado. Além disso, essas operações colaboram para a construção da identidade discursiva não somente do jornal, mas também dos actantes, que passam a ser vistos em função da imagem resultante da estruturação enunciativa de suas falas.

Palavras-chave: enunciação; embreagem; debreagem; imparcialidade.

Abstract: Enunciative strategies in the production of impartiality effects on news - This paper investigates how enunciative strategies produce meaningful effects of impartiality on news. In order to achieve our goals, we use discursive semiotics as theoretical basis and analyse the enunciative operations "shifting in" and "shifting out" mobilized in two pieces of news, one of them published in O Povo and the other one published in Diário do Nordeste, both newspapers from Fortaleza, in the state of Ceará. We understand that, while they regulate the presence of enunciation in enunciate, enunciative operations create different rates of exemption or commitment, to enunciator and actants. Besides, those operations cooperate to the construction of discursive identity, not only to the newspaper but also to the actants, which are seen according to the resulting image from the enunciative structuring of their utterance.

Keywords: enunciation; shifting in; shifting out; impartiality. 


\section{Introdução}

O discurso da mídia jornalística se caracteriza, por tradição, como imparcial. Arriscamos dizer que essa característica constitui um dos pilares da credibilidade e da imagem ética da mídia jornalística perante a sociedade (MIGUEL; BIROLI, 2010).

Dizer que um discurso é imparcial é assumir que ele "se abstém de tomar partido ao julgar ou ao constituir-se em julgamento", ou seja, é afirmar que possui "equidade" e "isenção", conforme o dicionário Houaiss (2009). Seguindo essa linha de raciocínio, caberia ao jornalista apresentar os fatos com máxima objetividade e neutralidade para que seu texto se apresentasse para o leitor como factual, como verdadeiro.

Sob o prisma da semiótica discursiva, entretanto, a verdade é concebida como um efeito de sentido produzido nos e pelos discursos. Logo, imparcialidade, neutralidade e objetividade não são termos realistas e absolutos, construídos, a priori, fora dos textos nos quais se manifestam. Pelo contrário, são efeitos de sentido criados por dispositivos enunciativos que funcionam como estratégias de manipulação extremamente eficazes no processo de comunicação. Desse modo, o que está em jogo é o "parecer verdadeiro", ou melhor, o "fazer parecer verdadeiro", fundado em um contrato enunciativo que se estabelece entre os participantes da comunicação, o enunciador e o enunciatário.

Neste artigo, tomamos como fundamentação teórica o aparato conceitual-analítico da semiótica discursiva de linha francesa, erigida por A. J. Greimas e seguidores, para analisar duas notícias, uma publicada na página online do Diário do Nordeste e outra publicada no sítio virtual do jornal O povo, ambos periódicos da cidade de Fortaleza, no Ceará. São notícias sobre fatos que se relacionam a demandas cotidianas da população dirigidas aos órgãos públicos.

É nosso objetivo examinar como as operações enunciativas de debreagem e embreagem produzem efeitos de sentido de imparcialidade. Supomos que, ao regularem a presença da enunciação no enunciado, as operações enunciativas criam diferentes graus de isenção ou comprometimento, tanto do enunciador quanto dos actantes do enunciado, com os fatos noticiados. É, portanto, por meio desses efeitos de sentido que se pode depreender a identidade discursiva de um jornal, como, por exemplo, tendencioso, neutro ou sensacionalista.

\section{A enunciação em semiótica}

No Dicionário de semiótica, Greimas e Courtés (2008, p. 166) afirmam que, a depender de pressupostos epistemológicos implícitos ou explícitos, enunciação pode ser definida de duas maneiras: como ato de linguagem singular e referencial, considerado sempre em uma situação de comunicação, ou como "instância linguística, logicamente pressuposta pela própria existência do enunciado (que dela contém traços e marcas)". 
A semiótica discursiva abraça a segunda definição por, no mínimo, duas razões: a primeira é que "a enunciação individual" não pode ser vista como um ato de fala singular, um enunciado isolado, independente do imenso corpo de enunciações coletivas que o precederam e que o tornam possível (BERTRAND, 2003). Além disso, essa singularidade e essa independência dão uma feição psicologizante e realista à noção de sujeito e de ato enunciativo, o que contradiz os postulados epistemológicos da semiótica. A segunda razão é que, para os autores do dicionário, a pressuposição lógica existente entre enunciação e enunciado, presente na segunda definição, desfaz a confusão, bastante corrente, que se faz entre a enunciação propriamente dita e a enunciação enunciada (ou narrada), tendo em vista que o modo de existência da primeira é simplesmente ser o pressuposto lógico do enunciado, enquanto a segunda deve ser tomada como sendo o conjunto de marcas, identificáveis no texto, que remetem à instância de enunciação.

Isso equivale a dizer que somente temos acesso ao sujeito, tempo e espaço da enunciação por meio de marcas deixadas no enunciado, ou seja, pelos elementos que remetem à instância da enunciação, como, por exemplo, pronomes pessoais, alguns adjetivos e advérbios valorativos, ou ainda, os dêiticos espaciais e temporais.

Sob esse viés, a enunciação aparece como uma "instância de mediação, que assegura a colocação em enunciado-discurso das virtualidades da língua" (GREIMAS; COURTÉS, 2008, p. 166). Ou ainda, conforme já asseverava Benveniste (1991), a enunciação é o lugar do ego, hic et nunc, isto é, do eu, aqui e agora. Como a pessoa (ego) enuncia num dado espaço e num determinado tempo, todo espaço e todo tempo organizam-se em torno do "sujeito", tomado como ponto de referência. Assim, a enunciação é a instância constitutiva do enunciado, cujo centro é o eu, sujeito que enuncia, num aqui e num agora.

Vale notar que a semiótica apresenta o sujeito da enunciação como sujeito semiótico, que, antes de ser "uma substância", ou sequer "a emanação (reflexo) de uma substância primeira que lhe seria exterior e que o determinaria", é forma, "produto de uma organização formal (discursiva), um efeito de sentido" que se pode tomar "como o pressuposto ou a resultante do discurso realizado" (LANDOWSKI, 1992, p. 168).

Como bem diz Bertrand (2003, p. 82-83), o sujeito do discurso "é uma instância em construção, sempre parcial, incompleta e transformável, que apreendemos a partir dos fragmentos do discurso realizado". Sendo assim, é no ato enunciativo que tanto o enunciado quanto o sujeito da enunciação são gerados.

A estrutura da enunciação comporta duas instâncias: a do enunciador e a do enunciatário; ambos vistos como funtivos reconstituíveis pela relação pressupositiva que mantêm com o enunciado-discurso (GREIMAS; COURTÉS, 2008). De acordo com Barros (1988), em semiótica, quando o enunciado é analisado na perspectiva de sua produção, pode-se compreender o sujeito da enunciação como um simulacro resultante do sincretismo entre enunciador e enunciatário. Mas, se o enunciado for examinado sob o ponto de vista da estrutura da comunicação, enunciador e enunciatário serão entidades 
discretas próprias da sintaxe comunicacional, em que o enunciador desempenha o papel de destinador-manipulador, e o enunciatário, o de destinatário-julgador da comunicação. Por isso, costuma-se dizer que a semiótica interpreta o processo de comunicação à luz da narratividade, para promover o que Landowski (1992) chama de "narrativização da enunciação".

Tudo se passa como se o sujeito da enunciação, ao produzir o enunciado, convocasse as estruturas semionarrativas virtuais para atualizá-las em discurso, e, neste processo de discursivização daquelas estruturas, ele assumisse o duplo papel actancial de enunciador e enunciatário. Mas, ao comunicar o discurso enunciado, o sujeito da enunciação se discretizasse e assumisse apenas o papel de enunciador, apresentando-se, neste caso, o processo de discursivização como um lugar de troca entre enunciador e enunciatário.

É lícito afirmar, portanto, que o enunciado não é apenas objeto de transmissão de saber, mas um objeto-discurso construído e manipulado pelo sujeito da enunciação. A partir dessa perspectiva, o processo comunicativo não pode ser reduzido à mera circulação de mensagens entre um emissor e um receptor num dado contexto, na medida em que o interesse da semiótica se volta para o jogo de "persuasão-manipulaçãointerpretação" intersubjetiva, próprio do processo comunicativo.

\section{As operações enunciativas}

A instância enunciativa pode ser simulada no interior de um enunciado, criandose assim ilusões enunciativas em que o eu enunciador assume papéis diferentes. Desse modo, temos o par enunciador / enunciatário como actantes implícitos por figurarem como pressupostos do ato enunciativo; o par narrador / narratário, categorias projetadas no interior do enunciado, sujeitos da enunciação enunciada simulada no texto; e o par interlocutor / interlocutário, sujeitos que interagem num outro quadro enunciativo, dessa vez, simulados pelo narrador. Se assumirmos a enunciação como um jogo de construção de simulacros, são, portanto, simulacros o sujeito da enunciação, o enunciador, o enunciatário, o narrador, etc.

Do ponto de vista semiótico, são dois os mecanismos enunciativos responsáveis pela produção desses simulacros, pela instauração de pessoas, tempos e espaços no enunciado: a debreagem e a embreagem (GREIMAS; COURTÉS, 2008). A descrição exaustiva desses mecanismos excede a finalidade deste artigo. Por esse motivo, faremos apenas uma apresentação sumária, que sirva de fundamentação teórica para nossa análise. Para uma leitura aprofundada do tema, remetemos o leitor à obra As astúcias da enunciação, de Fiorin (2002).

Greimas e Courtés (2008, p. 111) assim definem a debreagem:

Operação pela qual a instância da enunciação disjunge e projeta fora de si, no ato de linguagem e com vistas à manifestação, certos termos ligados à sua estrutura de base, para assim constituir os elementos que servem de fundação ao enunciado-discurso. 
De acordo com Fiorin (2002, p. 43), a debreagem consiste, em um primeiro momento, "em disjungir do sujeito, do espaço e do tempo da enunciação e em projetar no enunciado um não eu, um não aqui e um não agora". Trata-se da projeção de categorias semânticas operadas pelo sujeito que enuncia a fim de instalar o universo de sentido, já que o puro vivido não é comunicável. Mediante esse ato, inaugura-se o enunciado ao mesmo tempo em que, de maneira implícita, articula-se a própria instância da enunciação.

Há dois tipos de debreagem: a enunciativa e a enunciva. A primeira instala no enunciado os actantes (eu/tu), o espaço (aqui) e o tempo (agora) da enunciação. A segunda instaura no enunciado os actantes (ele/eles), o espaço (algures) e o tempo (então) do enunciado.

Por meio das debreagens enunciativa e enunciva, obtêm-se no discurso dois grandes efeitos de sentido: a) de subjetividade, quando os simulacros do ego-hic-nunc enunciativos instalados no enunciado geram um efeito de aproximação, de apreciação de fatos; e b) de objetividade, quando o apagamento das marcas da enunciação no enunciado produz um efeito de distanciamento, de imparcialidade. Uma vez que a instância da enunciação pode ser concebida como o sincretismo do "eu-aqui-agora", teremos respectivamente uma debreagem actancial, espacial e temporal, tanto enunciativa quanto enunciva.

A debreagem actancial enunciativa instala no enunciado o simulacro do eu enunciador, a debreagem espacial enunciativa ordena o espaço do enunciado em função do aqui enunciativo e a debreagem enunciativa temporal instala no enunciado termos ordenados em relação ao agora da enunciação. A título de exemplificação, teríamos, na frase "Eu estive aqui ano passado", a coexistência dos três tipos de debreagem enunciativa, marcadas, respectivamente, pelo pronome pessoal, pelo dêitico espacial e pelo dêitico temporal. As debreagens enuncivas actancial, espacial e temporal, por sua vez, instalam no enunciado seus actantes (ele, eles), seu espaço (algures) e seu tempo (então). Retomando o mesmo exemplo, o enunciado debreado enuncivamente poderia ser assim formulado: "Roberto esteve no Rio de Janeiro em dezembro de 2015".

Conforme podemos observar, o mecanismo de debreagem consiste em pluralizar a instância de discurso, a fim de que possa comportar, ainda que virtualmente, uma infinidade de espaços, tempos e atores.

Ao contrário da debreagem, que expulsa da instância da enunciação os termos categóricos (atores, tempo e espaço) do enunciado, a embreagem consiste em um "efeito de retorno à enunciação, produzido pela suspensão da oposição entre certos termos da categoria da pessoa e/ou do espaço, e/ou do tempo, bem como pela denegação da instância do enunciado" (GREIMAS; COURTÉS, 2008, p. 159-160).

Com isso, produz-se a impressão de identificação entre as categorias de pessoa, espaço e tempo do enunciado e da enunciação. Temos uma embreagem actancial quando ocorre uma neutralização da categoria de pessoa (por exemplo, quando o próprio presidente da república diz "O presidente da república não mede esforços para preservar a democracia", há uma neutralização da oposição eu/ele). Na embreagem temporal, 
temos a neutralização da categoria de tempo (por exemplo, quando neutralizamos a oposição entre pretérito perfeito e presente do indicativo em uma frase como "Fui à festa ontem à noite e encontro Júlia, que não via há muito tempo"). Já na embreagem espacial, neutraliza-se a categoria de espaço (como exemplo, temos a utilização do verbo "vir", que remete ao espaço da enunciação: "Todos os reis responderam (...) que eles teriam muito prazer em vir ao congresso").

É importante lembrar que todo ato embreante pressupõe uma debreagem, que Ihe é logicamente anterior. Segundo Greimas e Courtés (ibidem, p. 160), "é impossível conceber a embreagem total; ela equivaleria a apagar toda marca do discurso, seria a volta ao inefável".

Para Saraiva e Leite (2013, p. 41), neste processo de debreagens e embreagens sucessivas, "toda enunciação simulada no interior de um discurso referencializa o simulacro da enunciação anterior, conferindo-lhe uma impressão de realidade. Mas, é bom que se diga, essa referencialização não passa de um efeito de discurso". Por isso é que podemos dizer que não lidamos, em discurso, senão com simulacros.

\section{A imparcialidade como efeito de sentido em notícias jornalísticas}

Analisaremos a seguir duas notícias retiradas de dois periódicos da cidade de Fortaleza, Diário do Nordeste e O povo. Como já dissemos, são notícias sobre fatos que se relacionam a demandas cotidianas da população dirigidas aos órgãos públicos.

Vejamos a primeira notícia':

Moradores cobram saneamento básico para o bairro

1. As residências do bairro Aeroporto não possuem saneamento básico. Assim, é comum ver o esgoto escorrendo a céu aberto pelas vias. "Essa lama vem toda para a porta da gente. O bairro é esquecido", reclama a dona de casa Maria Laurizita Freitas. 2. Além disso, os moradores temem pelos riscos de transmissão de doenças através da água servida. Resposta: 1. A Companhia de Água e Esgoto do Ceará (Cagece) informa que já há um projeto para a instalação da rede de saneamento básico no bairro. "O projeto prevê a execução de 850 ligações domiciliares de esgoto, de 4.035,14 metros de rede coletora, de uma estação elevatória de esgoto e de 1.057 metros de linha de recalque", afirma a companhia, em nota. Atualmente, a Cagece aguarda a liberação dos recursos pela Caixa Econômica Federal (CEF), já que a obra está incluída no Programa de Aceleração ao Crescimento (PAC) 2. A previsão é de que as obras sejam iniciadas até o primeiro semestre do próximo ano.

Do ponto de vista enunciativo, essa noticia se apresenta por meio de uma debreagem enunciva actorial. Esse tipo de debreagem é traço característico do discurso jornalístico para se mostrar imparcial, pois a presença dos verbos em terceira pessoa instaura um "ele" no texto-enunciado, produzindo um efeito de sentido de distanciamento e consequente neutralidade do enunciador em relação aos conteúdos enunciados.

1 Notícia retirada da página online do Jornal O povo, do dia 04/07/2013, coluna "O povo nos bairros". Disponível em: http:/www.opovo.com.br/app/colunas/opovonosbairros/2013/07/04/noticiasopovonosbairros,3085968/ aeroporto-o-bairro-marcado-pelo-barulho-das-turbinas-das-aeronaves.shtml. Acesso: 18 Jan. 2015. 
O efeito de imparcialidade da notícia, contudo, não é absoluto e não se manifesta somente por meio dessa marca enunciativa, como veremos. Se tomarmos como ponto de partida a configuração narrativa do texto, observaremos que há um actante-sujeito, a população, que exige o fazer de outro actante-sujeito, a Cagece, que, por sua vez, pressupõe-se preencher todas as condições para realizar a ação pela qual foi cobrada, ou seja, sabe e pode fazer o saneamento; no entanto, não o faz. Partindo-se dessa suposição, depreensível da própria reivindicação da população, de que a Cagece possui a competência modal para fazer (não só sabe e pode, mas também deve) e, mesmo assim, não faz, o texto coloca em suspeição a modalidade do querer, admitindo-se, desse modo, a possibilidade de um não-querer-fazer por parte da Cagece. Com isso, o sujeito que está sendo cobrado vê-se sancionado negativamente em seu percurso narrativo. Conforme veremos em detalhes mais adiante, a própria Cagece, em sua resposta, altera a configuração de sua competência, apresentando o fazer prévio do actante Caixa Econômica como condição para o seu fazer. Assim, ela se coloca como um sujeito que sabe, deve e quer fazer. Só não faz porque seu "poder fazer" depende de outro actante.

Por outro lado, não podemos negar que, a despeito da debreagem enunciva (do discurso em terceira pessoa), essa trama narrativa insere certo grau de subjetividade na notícia, ao colocar em cena o possível (não) querer fazer da Cagece. Para reforçar esse fato, o enunciador introduz a fala de uma moradora do bairro com o verbo dicendi "reclamar". A escolha desse verbo cria um duplo efeito de sentido, tanto de objetividade quanto de subjetividade. De objetividade porque o verbo está debreado em terceira pessoa; de subjetividade porque se trata de um verbo com carga semântica valorativa, diferentemente dos considerados neutros, utilizados geralmente pela mídia jornalística como introdutores de fala reportada para criar o efeito de imparcialidade, como, por exemplo, os verbos "informar" e "afirmar". O verbo "reclamar" matiza o efeito de imparcialidade produzido pela debreagem enunciva (verbo em terceira pessoa), na medida em que instaura, ainda que sutilmente, o ponto de vista do enunciador sobre o ato de fala da moradora, reforçando o tom de provocação entre população e Cagece.

A resposta do órgão público também vem marcada no texto por uma debreagem enunciva actorial, que, como já vimos, funciona como estratégia para manter o afastamento e a isenção do jornal diante do narrado. Entretanto, também são mobilizados mecanismos que produzem, aqui, efeitos de sentido responsáveis por graduar esse afastamento e essa isenção.

Do modo como o jornal apresenta a resposta do órgão público, a responsabilidade da Cagece na realização do saneamento no bairro é relativizada, uma vez que sua ação depende da ação prévia de outro sujeito, a Caixa Econômica Federal ("aguarda a liberação de recursos financeiros pelo banco para poder executar a obra de saneamento"). Tal expediente coloca, assim, a instituição bancária em uma condição narrativa ambígua, comportando-se tanto como adjuvante na realização da obra, quanto como antissujeito, já que, por não ter ainda liberado os recursos, pode ser vista como um óbice para que a Cagece realize o saneamento. 
Outro dado interessante diz respeito aos verbos utilizados na resposta dada pela Cagece. No mesmo sentido do que vimos com "reclamar", em ocorrência já analisada, percebemos que, embora os verbos estejam todos debreados enuncivamente, não podem ser lidos da mesma maneira. Enquanto os verbos "informar" e "afirmar" são indicadores mais próximos da neutralidade, servindo, primordialmente, para o enunciador delegar a fala para o actante do enunciado, o mesmo não se pode dizer dos verbos "aguardar" e "prever". Esses últimos são verbos que projetam as ações para o futuro e que não especificam, do ponto de vista de uma semântica dos papeis temáticos, o controle da ação por parte do sujeito. Tem-se aqui uma questão aspectual, na medida em que não temos acesso, pelo enunciado, nem à fase incoativa (inicial) e nem à terminativa (final) do processo. Com isso, delineia-se, no nível discursivo, uma isotopia temática de incerteza, de dúvida em relação ao momento em que se iniciará a obra de saneamento do bairro, uma vez que a ação que costuma ser apresentada como pontual ganha inusitada duratividade, em virtude dos verbos utilizados.

É preciso destacar também que esses verbos são parte de enunciados estereotipados, fórmulas discursivas programadas, muito recorrentes e repetidas na fala dos órgãos públicos, quando precisam se justificar ou responder publicamente as demandas da população ("O projeto prevê a execução...", "a Cagece aguarda a liberação dos recursos..." e "A previsão é de que as obras sejam iniciadas até..."). Pela sua recorrência e repetição nos mais diversos discursos, esses enunciados, quase sempre debreados enuncivamente, criam para o enunciatário uma espécie de enunciador coletivo. Ou seja, um enunciador dessemantizado, descomprometido, depreendido de enunciados memorizados coletivamente, equivalentes às fraseologias ou aos protocolos verbais. Diante disso, na notícia em tela, a presença desses enunciados pode ser vista como uma estratégia enunciativa para promover o máximo de distanciamento dos actantes do enunciado daquilo que está sendo enunciado.

Passemos à análise de outra notícia²:

\section{Acidente $^{3}$}

Francisco Joceliano sofreu duas descargas elétricas, por volta das 10h com intervalo de 15 minutos de uma para outra, mas a primeira já foi suficiente para deixá-lo desacordado. Ele passou cerca de uma hora e meia preso ao poste enquanto o socorro era acionado e a rede elétrica desligada pela Coelce, para que o resgate fosse feito.

O eletricista ainda foi resgatado com vida pelo Corpo de Bombeiros e levado ao Instituto José Frota (IJF) por uma equipe do Samu. "A gente acionou o pessoal da Coelce para fazer o desligamento da rede de alta tensão, de 69 mil volts. Quando se deu o desligamento, pegamos a plataforma e subimos com um técnico da Coelce para verificar. Depois disso, subimos novamente para fazer a retirada dele", afirma o capitão Carlos Albert, chefe da equipe do Corpo de Bombeiros que atendeu à ocorrência. Segundo a assessoria do hospital, Francisco chegou à unidade em estado gravíssimo, com $90 \%$ do corpo queimado, e foi encaminhado à sala de reanimação. Ele ainda foi entubado, mas não resistiu aos ferimentos. O óbito foi confirmado às $12 \mathrm{~h} 30$.

Em nota, a Coelce lamentou o ocorrido e disse que prestará toda a assistência necessária à família do funcionário. "A Coelce informa, ainda, que adota rigorosos padrões de segurança em suas atividades e capacita, periodicamente, funcionários próprios e parceiros com base em normas nacionais e internacionais de segurança", diz o órgão.

2 Notícia retirada da página online do Jornal Diário do Nordeste, do dia 25/10/2014, coluna "Cidade". Disponível em: http://diariodonordeste.verdesmares.com.br/cadernos/cidade/funcionario-morre-eletrocutado-e-bairros-saoafetados-por-apagao-1.1134372. Acesso: 25 Jan. 2015.

3 A manchete principal da notícia é "Falta de energia. Funcionário morre eletrocutado e bairros são afetados pelo apagão". Na íntegra, a notícia se apresenta dividida em duas partes, a primeira trata da morte do funcionário e 
Do mesmo modo que a notícia analisada anteriormente, o texto é marcado pela presença de debreagens enuncivas, cujo propósito é apagar as marcas da enunciação no enunciado, produzindo efeitos de distanciamento e de neutralidade. Entretanto, várias expressões textuais relativizam esses efeitos de sentido. Podemos citar, por exemplo, o advérbio "já" e a locução adverbial "cerca de", destacados na notícia (grifos nossos). A partícula adverbial "já" funciona no texto como um intensificador, de caráter avaliativo, que instaura um ponto de vista sobre o acidente. A locução, por seu turno, minimiza o efeito de objetividade da debreagem enunciva, pois produz uma imprecisão temporal que perspectiva, em termos aspectuais, a duratividade do evento ("cerca de uma hora e meia" pode compreender um intervalo maior ou menor de duração). Como se vê, ambas as expressões quebram o efeito de imparcialidade da notícia, tendo em vista que constituem marcas da presença da enunciação no enunciado.

A presença dessas e de outras marcas na notícia, pelo visto, não ocorre à toa. O jogo enunciativo do texto também deixa implícita uma atribuição de responsabilidade à Coelce pela demora no desligamento da rede elétrica. Essa atribuição de responsabilidade se dá de forma indireta, uma vez que o enunciador da notícia delega a voz a um actante do enunciado, o Capitão do Corpo de Bombeiros, por meio de uma debreagem enunciva, no entanto, dentro do trecho em aspas, ocorre uma debreagem enunciativa, pois o Capitão do Corpo de Bombeiros assume o discurso em primeira pessoa.

É importante destacar, ainda, que a maneira como é organizada a fala do Capitão, em uma sequência de ações que parece buscar reproduzir a demora no socorro ao eletricista, produz um efeito de duratividade que enfatiza a responsabilização da Coelce. No trecho que aparece em seguida, lemos: "segundo a assessoria do hospital, Francisco chegou à unidade em estado gravíssimo, com 90\% do corpo queimado, e foi encaminhado à sala de reanimação. Ele ainda foi entubado, mas não resistiu aos ferimentos". Esse encadeamento das informações também não parece aleatório, posto que, logo após a ênfase na duratividade de todo o processo de socorro ao eletricista, coloca-se a informação acerca de seu estado ao chegar ao hospital e sua consequente morte.

Apesar de o texto construir essa culpabilidade, na resposta da Coelce, nada é dito sobre a demora para realizar o desligamento da rede elétrica. Mais ainda, a resposta da empresa de fornecimento de energia consiste praticamente em um bloco de enunciados estereotipados, estratégia também mostrada na análise da notícia anterior.

Ainda acerca da resposta da Coelce, observamos, inicialmente, a presença da debreagem enunciva, uma vez que o enunciador-jornal faz uso do discurso indireto, lançando mão da terceira pessoa e alcançando, desse modo, um primeiro efeito de afastamento. Em seguida, ao recorrer às aspas e inserir a própria fala da Coelce, reforça ainda mais seu afastamento com relação ao que é colocado pela empresa.

a segunda se refere à falta de energia nos bairros, sem fazer nenhuma remissão aos fatos relatados na primeira. Por conta dessa relativa independência, bem como para os objetivos deste artigo, optamos por fazer um recorte, ficando somente com a primeira parte da notícia, cujo título é "Acidente", relativa à morte do funcionário, conforme se vê no quadro. 
Chama atenção, também, a operação de embreagem que vemos dentro das aspas, dessa vez, realizada pela própria Coelce. Em uma situação na qual se esperaria a primeira pessoa, esta se apresenta em terceira pessoa, criando um efeito de distanciamento do fato. O efeito produzido, consequentemente, é o de uma sequência de afastamentos: há a debreagem realizada pelo enunciador-jornal, que se afasta do que é dito ao dar a voz à empresa (primeiramente, fazendo uso do discurso indireto e, em seguida, do discurso direto, em um processo de gradativa intensificação do afastamento) e, dentro da fala da empresa, há uma embreagem, realizada pelo actante Coelce, que, ao falar de si mesmo em terceira pessoa, também se distancia do que afirma.

Encontra-se aí, portanto, uma espécie de "efeito-dominó" na busca por isenção de responsabilidades que, no caso da Coelce, evidencia um trabalho de construção textual do distanciamento, levado a cabo pela empresa e sustentado, principalmente, pelo recurso aos enunciados estereotipados, que se sucedem do início ao fim de sua resposta, e pelo uso da neutralização entre primeira e terceira pessoa (embreagem), ao falar de seus próprios posicionamentos acerca do ocorrido.

Assim, conforme observamos, nesta notícia e na anterior, é possível perceber que as operações enunciativas produzem ora efeitos de objetividade, ora de subjetividade e, com isso, regulam o grau de comprometimento ou isenção tanto do enunciador quanto dos actantes do plano do enunciado diante dos fatos noticiados.

\section{Considerações finais}

A imparcialidade jornalística, de acordo com as análises das notícias, nada mais é do que um efeito de sentido, resultante dos graus de presença da enunciação no enunciado, regulados, dentre outras coisas, pelas operações de debreagem e embreagem. Esse jogo enunciativo dilui a fronteira entre aquilo que seria estritamente da ordem do enunciado e o que seria da ordem da enunciação, e responde, em certa medida, pela eficácia persuasiva do discurso jornalístico. Logo, a presença de debreagens enuncivas no discurso jornalístico, utilizadas para marcar o efeito de imparcialidade, não implica completa isenção do enunciador perante os fatos noticiados.

Ao gerar efeitos de sentido de objetividade e/ou subjetividade, bem como de aproximação e/ou afastamento, as operações enunciativas podem orientar a leitura do enunciatário, levando-o a aderir (ou não) ao universo de valores e crenças colocado em discurso pelo enunciador. Além disso, essas operações colaboram para a construção da identidade discursiva não somente do jornal, mas também dos actantes do enunciado, que passam a ser vistos em função da imagem resultante da estruturação enunciativa de suas falas.

Se assumirmos a enunciação como "o lugar da veridicção" e o discurso como o "espaço frágil em que se inserem e se lêem a verdade e a falsidade, a mentira e o segredo" (GREIMAS, 2014, p. 117), acompanhar esse jogo de simulacros criados pelas operações 
enunciativas pode revelar, assim cremos, as relações intersubjetivas de manipulação produzidas nesse campo de presença discursivo, que é a mídia jornalística.

Ricardo Lopes Leite é professor adjunto IV do Departamento de Letras Vernáculas e do Programa de Pós-Graduação em Linguística da Universidade Federal do Ceará (UFC); é coordenador do Grupo de Estudos Semióticos da Universidade Federal do Ceará - SEMIOCE. É doutor em Linguística pela Universidade Federal do Ceará.

rleite32@hotmail.com

Otavia Marques de Farias é docente da Universidade da Integração Internacional da Lusofonia Afro-Brasileira (Unilab). É doutora em Linguística pela UFC.

otaviamarques@gmail.com

\section{Referências}

BARROS, D. L. P. Teoria do discurso: fundamentos semióticos. São Paulo: Atual, 1998.

BENVENISTE, E. Problemas de linguística geral I. Campinas: Pontes, 1991.

BERTRAND, D. Caminhos da semiótica literária. Bauru: EDUSC, 2003.

FIORIN, J. L. As astúcias da enunciação. São Paulo: Ática, 1996.

GREIMAS, A. J. A enunciação: uma postura epistemológica. Significação: Revista Brasileira de Semiótica, Ribeirão Preto, n.1, p. 9-25, 1974.

GREIMAS, A. J. Sobre o sentido II: ensaios semióticos. São Paulo. Nankin/EDUSP, 2014.

GREIMAS, A. J; COURTÉS, J. Dicionário de semiótica. São Paulo: Contexto, 2008.

HOUAISS, A. Dicionário eletrônico Houaiss da língua portuguesa. São Paulo: Objetiva, 2009.

LANDOWSKI, E. A sociedade refletida: ensaios de sociossemiótica. São Paulo: EDUC: Pontes, 1992.

MIGUEL, L. F \& BIROLI, F. A produção da imparcialidade: a construção do discurso universal a partir da perspectiva jornalística. Revista brasileira de ciências sociais. São Paulo, v. 25, n. 73, p. 59-76, 2010. Disponível em: <http://www.scielo.br/pdf/rbcsoc/v25n73/v25n73a04.pdf>. Acesso em: 20 Ago. 2015.

SARAIVA, J. A. B; LEITE, R. L. Efeitos metafóricos e graus de presença da enunciação no enunciado. Alfa: Revista de linguística (UNESP. Online), v. 57, p. 37-51, 2013. 